\title{
Provenance and threat-sensitive predator avoidance patterns in wild- caught Trinidadian guppies
}

Grant E. Brown ${ }^{1}$, Camille J. Macnaughton ${ }^{1}$, Chris K. Elvidge ${ }^{1}$, Indar Ramnarine ${ }^{2}$, and Jean-Guy J. Godin ${ }^{3}$

${ }^{1}$ Department of Biology, Concordia University, 7141 Sherbrooke St. W., Montreal, QC, H4B 1R6, Canada

${ }^{2}$ Department of Life Sciences, University of the West Indies, St. Augustine, Trinidad and Tobago

${ }^{3}$ Department of Biology, Carleton University, 1125 Colonel By Drive, Ottawa, ON, K1S 5B6, Canada

*Address for Correspondence: Grant E. Brown, Department of Biology, Concordia University, 7141 Sherbrooke St. West, Montreal, QC, H4B 1R6, Canada. Telephone: +1 514-848-2424, ext. 4020, Telefax: +1 514-848-2881, email: gbrown@alcor.concordia.ca

Running Head: Threat-sensitive response to guppy alarm cues

Keywords: Threat-sensitivity, predator avoidance, guppy, chemical alarm cue, population differences, long-term predation risk

Originally published in Behavioral Ecology and Sociobiology (2009) 63, 699-706. DOI 10.1007/s00265-008-0703-4

Copyright: Springer Verlag 


\begin{abstract}
The antipredator behaviour of prey organisms is shaped by a series of threat-sensitive trade-offs between the benefits associated with successful predator avoidance and a suite of other fitness-related behaviours such as foraging, mating and territorial defence. Recent research has shown that the overall intensity of antipredator response and the pattern of threat-sensitive trade-offs are influenced by current conditions, including variability in predation risk over a period of days to weeks. Here, we tested the hypothesis that long-term predation pressure will likewise have shaped the nature of the threat-sensitive antipredator behaviour of wild-caught Trinidadian guppies (Poecilia reticulata). Female guppies were collected two populations that have evolved under high- and low-predation pressure, respectively, in the Aripo River, Northern Mountain Range, Trinidad. Under laboratory conditions, we exposed shoals of three guppies to varying concentrations of conspecific damage-released chemical alarm cues. Lower Aripo (high-predation) guppies exhibited the strongest antipredator response when exposed to the highest alarm cue concentration and a graded decline in response intensity with decreasing concentrations of alarm cue. Upper Aripo (low-predation) guppies, however, exhibited a nongraded (hypersensitive) response pattern. Our results suggest that long-term predation pressure shapes not only the overall intensity of antipredator responses of Trinidadian guppies, but also their threat-sensitive behavioural response patterns.
\end{abstract}

\title{
Introduction
}

The threat-sensitive predator avoidance hypothesis (Helfman 1989) predicts that prey individuals should be selected to adjust the form and/or intensity of their behavioural responses to a threat of predation in proportion to the level of the perceived threat. This ability to make such threat-sensitive behavioral decisions presumably allows prey to trade-off the often conflicting demands of successful detection and avoidance of potential predation threats against other fitness-related activities such as foraging, mating and territorial defence, so as to maximize fitness (Godin \& Smith 1988; Lima \& Dill 1990; Lima \& Steury 2005; Brown et al. 2006a). To date, the threat-sensitive predator avoidance hypothesis has received extensive support across a range of taxa, including aquatic invertebrates (e.g., Rochette et al. 1997), terrestrial invertebrates (e.g., Persons \& Rypstra 2001), amphibians (Laurila et al. 1997), reptiles (e.g., Amo et al. 2004), birds (e.g., Edelaar \& Wright 2006) and mammals (e.g., Swaisgood et al. 1999). In addition, several authors have shown threat-sensitive responses to both visual (Bishop \& Brown 1992; Chivers et al. 2001) and chemosensory cues (Lawrence \& Smith 1989; Dupuch et al. 2004; Brown et al. 2006a; Vavrek \& Brown in press) associated with a predation threat by a variety of prey fishes.

Threat-sensitive responses range from 'pure threat-sensitive' patterns to 'hypersensitive' ones (Helfman \& Winkleman 1997; Brown et al. 2006a), depending on the relative benefits of successful predator avoidance versus those associated with other activities such as foraging. In the case of pure threat-sensitive (graded) responses, prey exhibit antipredator behaviour at an intensity directly proportional to the level of perceived risk. Conversely, hypersensitive (non-graded) responses are characterized by 
prey responding at or near maximal intensity when a threat is detected above some minimum behavioral response threshold (Helfman \& Winkleman 1997; Brown et al. 2001). For example, Helfman (1989) and Helfman \& Winkleman 1997) examined the antipredator response patterns (i.e., visual reaction distance, duration of response) in two sympatric damselfish species exposed to model predator threats. Threespot damselfish (Stegastes planifrons), which are primarily benthic territorial herbivores, exhibit pure threat-sensitive antipredator responses to visual predator cues. However, the sympatric bicolour damselfish (Stegastes partitus) exhibits antipredator responses at or near maximal intensities when they detect a predation threat above some minimal level (i.e., hypersensitive response), likely due to their more risky planktivorous foraging tactics (Helfman \& Winkleman 1997). More recently, Brown et al. (2006a) have shown that juvenile convict cichlids (Amatitlania nigrofasciata) shift from a non-graded to a graded response pattern as shoal size increased. The form of the threat-sensitive response pattern should be shaped by the relative benefits associated with successful predator avoidance versus those associated with other fitness-related behaviours. Thus, moment to moment changes in the local risk of predation can shape threat-sensitive trade-offs (Lima \& Bednekoff 1999; Brown et al. 2006a).

Variability in the ambient level of predation risk over periods of a few days to weeks is also known to influence the antipredator responses of prey. Lima and Bednekoff (1999) and Sih et al. (2000) argued that the degree of variability in the level of risk should dictate the nature of the trade-offs between predator avoidance and other activities. In fact, a growing body of literature shows that, in an environment characterized by frequent predation threats, prey exhibit significantly lower intensities of antipredator behaviour when they perceive a predation threat and increased foraging activity in the absence of any perceived threat (e.g., Hamilton \& Heithaus 2001; Sih \& McCarthy 2002; Koivisto \& Puesenius 2003; Foam et al. 2005a; Ferrari et al. 2008). Brown et al. (2006b) have recently shown that such variability in ambient predation risk influences the threat-sensitive decisions made by juvenile convict cichlids. Cichlids preexposed to a high-frequency risk treatment exhibited lower intensity antipredator responses than did cichlids under a low-frequency risk treatment. However, highfrequency treatment cichlids compensated for their reduced response intensity by responding at considerably lower levels of predation threat (Brown et al. 2006b). Thus, it is becoming increasingly clear that threat-sensitive behavioural responses are shaped by both immediate cost-benefit trade-offs and short-term variability in predation risk. Any immediate or short-term factor that increases potential foraging benefits (or some other fitness related activity) relative to antipredator benefits should favour a graded-response pattern. However, factors that decrease foraging benefits relative to antipredator benefits should favour a hypersensensitive response pattern (Brown et al. 2006a).

Populations may also experience different ambient predation pressures over generational time scales. It is well established that long-term ambient predation pressure can determine the overall intensity of antipredator behaviour in a number of prey fishes (Giles \& Huntingford 1984; Kelley \& Magurran 2006), including the Trinidadian guppy (Magurran 2005). Such effects may be due to multigenerational selection or individual experience within a generation (Magurran 2005), or both. However, it is unknown if 
long-term predation pressure shapes the threat-sensitive response pattern (i.e., graded versus nongraded). In the current laboratory study, we addressed the question of how longer-term predation risk might have shaped threat-sensitive antipredator response patterns in the Trinidadian guppy. Under laboratory conditions, we exposed guppies collected from high- and low-predation sites within the Aripo River (Northern Range Mountains, Trinidad) to conspecific chemical alarm cues at varying concentrations. A variety of taxonomically diverse freshwater prey fishes (Chivers \& Smith 1998; Wisenden \& Chivers 2006), including the Trinidadian guppy (Nordell 1998; Brown \& Godin 1999), rely on damage-released chemical alarm cues to assess local predation threats. These cues are typically found in the epidermis and are only released following mechanical damage, as would occur in a predation event (Chivers \& Smith 1998). Given the nature of their release, alarm cues are a reliable indicator of local predation threats (Brown 2003; Wisenden \& Chivers 2006). Previous work has shown that the relative concentration of alarm cue detected is a reliable indicator for the level of immediate predation threat in aquatic prey organisms (Lawrence \& Smith 1989; Dupuch et al. 2004; Ferrari et al. 2005; Brown et al. 2006a). Here, we predicted that, given the comparatively high frequency and high risk of predation experienced by guppies from the Lower Aripo River (high-predation population), they should exhibit a more intense overall antipredator response and a more graded (proportional) response to chemical alarm cues compared to guppies from the Upper Aripo River (low-predation population).

\section{Methods}

Study populations and fish collection

We collected adult female guppies, using beach and hand seines, from the two locations within the Aripo River, Northern Mountain Range, Trinidad. The Lower Aripo population is characterized as a 'high-predation' site (Magurran 2005), containing several species that prey on juvenile and adult guppies, including pike cichlids (Crenichichla alta), blue acara cichlids (Aequidens pulcher), and black acara cichlids (Cichlasoma bimaculatum). In addition, there are several predators which prey on small, juvenile guppies, including Hart's rivulus (Rivulus hartii) and the twospot astyanax (Astyanax bimaculatus). The Upper Aripo population is located above a barrier waterfall and contains only Hart's rivulus and a predatory freshwater prawn (Macrobrachium crenulatum), both of which are restricted to preying on small, juvenile guppies (Endler \& Houde 1995; Magurran 2005). As such, it can be characterized as a 'low-predation' site (Magurran 2005). Prior to being used either as stimulus donors or test fish, guppies were housed in $350 \mathrm{~L}$ glass aquaria at $\sim 24^{\circ} \mathrm{C}$ in the laboratory and fed twice daily with commercial flake food $\left(\right.$ Tetramin $\left.^{\mathrm{TM}}\right)$. The tanks were aerated and cleaned daily. Wildcaught guppies were allowed to adjust to laboratory conditions for at least 24 hours prior to testing and were used in behavioural triads within three days of collection in the field.

\section{Alarm stimulus preparation}

We collected alarm cue from non-gravid (assessed visually) female guppies from both the Upper and Lower Aripo River populations. Cue donors were sacrificed by cervical dislocation. We immediately removed the head and tail (at the caudal peduncle) and all internal visceral tissue. We placed the remaining tissue (skin and underlying skeletal muscle) into $100 \mathrm{~mL}$ of aged tap water. Tissue samples were then homogenized 
and filtered through polyester filter floss and diluted to the desired final volume with the addition of aged tap water. To control for any confound originating from population bias in the behavioural response to alarm cues (Brown \& Godin 1999, unpublished data), we blended equal quantities of alarm cue from Upper and Lower Aripo guppies and used the combined solution as our stimulus alarm cue.

We used 11 Upper Aripo females (mean \pm SD standard length $=2.65 \pm 0.37 \mathrm{~cm}$ ) and 14 Lower Aripo females $(2.34 \pm 0.35 \mathrm{~cm})$ as alarm cue donors. We collected a total of 31.66 and $31.84 \mathrm{~cm}^{2}$ of tissue surface area (Upper and Lower Aripo donors, respectively) and adjusted the final volume to $612 \mathrm{~mL}$. The final concentration $\left(\sim 0.1 \mathrm{~cm}^{2}\right.$ $\mathrm{mL}^{-1}$ ) was similar to those used in previous studies with the Trinidadian guppy (Brown \& Godin 1999, unpublished data). We froze the alarm cue in $25 \mathrm{~mL}$ aliquots at $-20^{\circ} \mathrm{C}$ until needed.

Experimental protocol

Behavioural observations of test fish were conducted in a series of $23 \mathrm{~L}$ glass aquaria filled with $18.5 \mathrm{~L}$ of dechlorinated tap water $\left(\sim 25^{\circ} \mathrm{C}\right)$. Each tank contained a single air stone and an additional $1.5 \mathrm{~m}$ length of airline tubing to allow for the injection of the chemical stimuli without disturbing the focal fish. To facilitate the quantification of area use (see below), we divided the tank into three equal horizontal sections by drawing lines along the front and back walls of the test tanks. At least $4 \mathrm{~h}$ prior to a trial, we placed shoals of three nongravid (assessed visually) female guppies into a test tank to acclimate. We chose to test shoals of three females as this particular shoal size falls within the natural range of guppy shoal sizes in nature (e.g., Magurran \& Seghers 1991) and to minimize the total number of guppies required. We used females as focal guppies because they tend to be more responsive to predation threats than males (Magurran 2005). Test guppies from were matched for body length, both within and between focal populations.

Trials consisted of a 5 min pre-stimulus and a 5 min post-stimulus injection observation period. Immediately prior to the pre-stimulus observation period, we withdrew and discarded $60 \mathrm{~mL}$ of tank water through the stimulus injection tube. We then removed and retained an additional $60 \mathrm{~mL}$ of tank water. Following the prestimulus observation, we injected $5 \mathrm{~mL}$ of stimulus alarm cue at one of four concentrations or $5 \mathrm{~mL}$ of aged tap water as a control, and slowly flushed the stimulus into the test tank using the retained $60 \mathrm{~mL}$ of tank water. Alarm cue was used either at the stock concentration $(100 \%)$ or diluted with dechlorinated tap water to $50 \%, 25 \%$ or $10 \%$ of stock concentration.

Once the stimulus was injected, we began the 5 min post-stimulus injection observation period. During both the pre- and post-stimulus observation periods, we recorded: 1) an index of area use, 2) a shoaling index, 3) the occurrence of dashing and freezing behaviour. Area use was recorded every $15 \mathrm{~s}$ as the position of each guppy within the tank ( $1=$ bottom third of the tank, $3=$ top third of the tank). Thus, possible area use scores ranged from 3 (all fish near the substrate) to 9 (all fish near the surface). We also recorded a shoaling index every $15 \mathrm{~s}$, which ranged from 1 (no fish within one 
body length of each other) to 3 (all fish within one body length of each other). Dashing was defined as a sudden burst of seemingly disoriented swimming, and freezing was defined as the cessation of all movement with the guppy settling to the substrate for at least $30 \mathrm{~s}$. For dashing and freezing, we recorded either their presence or absence within each 5-min observation period. A reduction in area use and an increase in shoaling index, dashing and/or freezing are typical antipredator responses towards conspecific alarm cues in guppies (Brown \& Godin 1999). We conducted 20 replicates per stimulus concentration for both Upper and Lower Aripo populations. Fish were used only once. Mean ( \pm SD) length at testing was $2.49 \pm 0.52 \mathrm{~cm}$. All observations were made blind to the experimental treatments (stimulus concentrations or control).

We calculated the change in area use and shoaling index between the pre- and post-stimulus observation periods (post - pre) and used these difference scores as dependent variables in all subsequent analyses. As both area use and shoaling index data had unequal variances, we tested for the effects of focal population and alarm cue donor population using the Scheirer-Ray-Hare extension of the Kruskall-Wallis test, which is a nonparametric analysis of variance (Sokal \& Rohlf 1995; Quinn \& Keough 2002). To directly test for graded versus non-graded response patterns, we conducted polynomial planned contrasts for area use and shoaling behaviour for each focal population separately (Quinn \& Keough 2002). Planned contrasts, as employed, test the total variance accounted for by linear versus quadratic models. The presence of significant quadratic terms suggests that the response pattern is best explained by a non-linear (nongraded) trend. For the occurrence of dashing and freezing behaviour, we tested for effects of focal population and alarm cue concentration using a two-factor G-test (Sokal \& Rohlf 1995).

\section{Results:}

Conspecific alarm cue concentration significantly affected both area use and shoaling index (Figure 1, Table 1), with guppies exhibiting significantly stronger responses with increasing concentrations of alarm cues. There was no significant main effect of focal population (Figure 1, Table 1). However, we did find a significant concentration by focal population interaction for both area use and shoaling index (Figure 1, Table 1), suggesting that the response pattern differed for Upper Aripo (low-predation) and Lower Aripo (high-predation) guppies. Planned contrasts analysis confirmed this observation. For the Upper Aripo population, both area use and shoaling index exhibited significant quadratic terms, whereas the Lower Aripo population exhibited only significant linear terms (Table 2, Figure 1). Significant linear terms suggest graded response patterns, whereas significant quadratic terms, over and above the linear term, suggest nongraded or hypersensitive response patterns (Table 2). In addition, we found significant stimulus concentration by focal population interactions in the occurrence of both dashing (Likelihood ratio $\left.\chi^{2}=18.19, \mathrm{df}=4, \mathrm{P}=0.001\right)$ and freezing $\left(\chi^{2}=16.07\right.$, $\mathrm{df}$ $=4, \mathrm{P}=0.003$ ) behaviour (Figure 2).

Our results show that, at the $100 \%$ stimulus concentration, the overall antipredator response intensity was highest for Lower Aripo (high predation) guppies and that response intensity decreased in a graded (proportional) fashion with decreasing stimulus 
concentration. Conversely, despite an overall lower intensity antipredator response to the highest stimulus concentration by Upper Aripo (low predation) guppies, decreasing stimulus concentration did not result in proportionally lower intensity responses. Thus, our results suggest differing response patterns to varying concentrations of conspecific alarm cues between these two study populations.

\section{Discussion}

Our results demonstrate that the overall intensity of antipredator behaviour and the form of threat-sensitive response patterns to conspecific chemical alarm cues in wildcaught Trinidadian guppies is dependant upon their provenance. When exposed to the highest test concentration of conspecific alarm cues, Lower Aripo (high-predation) guppies exhibited consistently higher responses intensity than did Upper Aripo (lowpredation) guppies. This finding is consistent with previous work, which demonstrates that guppies from high-predation populations respond with a higher overall intensity to a standardized predation threat than do those from low-predation populations (Magurran 2005). More important, however, is our novel finding that the pattern of threat-sensitive response is likewise dependent upon provenance. Our results reveal that guppies from the Lower Aripo site exhibited a graded threat-sensitive response pattern in which the intensity of antipredator behaviour was proportional to the concentration of alarm cue presented. In comparison, guppies from the Upper Aripo site exhibited a non-graded (hypersensitive) response pattern to the same range of alarm cue concentrations. Collectively, these findings support our hypothesis that long-term predation pressure shapes threat-sensitive behavioural trade-offs in prey organisms.

Although it is clear that threat-sensitive response patterns differ between the Upper and Lower Aripo River populations, it is unclear if this plasticity is due to population-specific experiences or the product of differential selection, or both. A wealth of evidence has shown that individual experience with predation pressure results in context-appropriate antipredator behavioural responses (reviewed in Brown 2003; Kelley $\&$ Magurran 2006). For example, guppies from high-predation populations exhibit more risk aversive behaviour patterns towards model predators compared to conspecifics from low-predation populations (Kelley \& Magurran 2003a,b). However, this difference was absent between their laboratory-reared offspring, demonstrating that experience and learning play an important role in shaping predator avoidance behaviour (Kelley \& Magurran 2003a,b). However, there is also strong evidence demonstrating the role of selection in the evolution of population-specific antipredator response patterns. For example, Magurran et al. (1992) examined the shoaling and predator inspection behaviour of laboratory-reared offspring of guppies transplanted from a high-predation to a low-predation population some 26-36 generations previously. They then compared their antipredator behaviour to that of the laboratory-reared offspring of the original highrisk population. Their results demonstrate that when individual experience is controlled

for, guppies transplanted from high- to low-predation sites exhibit typical 'low-predation site' antipredator responses. Thus, the results of Magurran et al. (1992) demonstrate that antipredator behaviour patterns can be modified by selection over multiple generations. Selection may act directly on the overall patterns of antipredator behaviour (i.e., direct genetic effects, O'Steen et al. 2002) or indirectly by favouring phenotypic plasticity 
(Magurran 2005). Clearly, future research should examine the non-mutually exclusive roles of experience and selection on the threat-sensitive response patterns of Trinidadian guppies.

Successful predator avoidance is costly in terms of time and energy available for other fitness-related activities (Lima \& Dill 1990; Welton et al. 2003; Lima \& Steury 2005). By exhibiting an antipredator response intensity proportional to the level of a perceived threat (i.e., alarm cue concentration), Lower Aripo guppies are likely to maintain foraging and courtship activities, albeit at a reduced level, under the risk of predation (Croft et al. 2004; Foam et al. 2005b). Alternatively, responding to frequent predation threats with high intensity predator avoidance behaviour would likely result in a dramatic reduction in fitness due to lost foraging or courtship benefits (Lima \& Bednekoff 1999; Sih et al. 2000). However, given that the frequency and/or intensity of predation threats are lower for Upper Aripo guppies, they may optimize threat-sensitive trade-offs by exhibiting 'maximal' antipredator responses whenever a threat is detected over some minimal behavioural threshold (Brown et al. 2001).

Our current results extend our understanding of factors that shape an individual's pattern of threat-sensitive behavioural decision making in animals. Brown et al. (2006a) have shown that juvenile convict cichlids switch from hypersensitive (nongraded) response as solitary individuals to a graded response pattern when tested in shoals of six conspecifics. Individuals tested alone or in small groups may be at a higher level of predation risk than are individuals in larger groups (Hoare et al. 2004). Thus, the elevated risk associated with small shoal size appears to shift the form of the threatsensitive response from a graded to a hypersensitive one. By doing so, individuals presumably gain antipredator benefits at the cost of lost foraging opportunities. Conversely, the threat reduction associated with larger shoal sizes might favour a more graded response pattern, which would allow prey to continue to forage whilst concurrently benefitting from a group-mediated reduction in individual risk of predation.

Likewise, Brown et al. (2006b) have shown that frequency of predation risk (temporal variability) over the period of a few days also influences threat-sensitive decision making. In this study, Brown et al. (2006b) pre-exposed cichlids to either an infrequent or a frequent predation threat regime and tested their response to varying concentrations of conspecific alarm cue. They found that cichlids pre-exposed to a high frequency of risk exhibited consistently lower intensity responses compared to those preexposed to a low frequency of risk, consistent with the predictions of the predation risk allocation hypothesis (Lima \& Bednekoff 1999; Ferrari et al. 2008). Moreover, cichlids appear to compensate for the reduced response intensity by lowering the threshold concentration of conspecific alarm cue needed to elicit an overt behavioural response (Brown et al. 2006b). Interestingly, Brown et al. (2006b) found that short-term variability in perceived predation threats did not induce a change in the pattern of response. They reported that cichlids exposed to high versus low frequencies of predation risk still exhibited a nongraded response pattern, suggesting that threatsensitive decisions are shaped by immediate factors (Vainikka et al. 2005; Brown et al. 2006b; Ferrari \& Chivers 2006). Thus, variability in local predation threats over multiple 
temporal scales interact to shape both the overall intensity and pattern of antipredator behaviour (Lima \& Bednekoff 1999; Brown et al. 2006 a,b; current study).

How prey perceive predation risk and how they integrate perce ived risk over multiple time scales are amongst the most important unanswered questions in the field of predator-prey dynamics (Lima \& Steury 2005). Previous studies have shown that both immediate and short temporal scale events can shape individual behavioural decisions. Our current results suggest that long-term predation pressure also influences threatsensitive decisions. Taken together, these studies highlight a high degree of intraspecific plasticity in behavioural decision making and suggest that the form of the threat-sensitive antipredator trade-off in prey is dynamic. Rather than simply adopting 'risk aversive' versus 'risk taking' strategies (Welton et al. 2003), the dynamic threat-sensitivity paradigm proposes that prey continually adjust their behavioural response according to immediate, intermediate or long-term patterns of predation risk (Brown et al. 2006a,b).

\section{Acknowledgements}

We thank Darren Croft, Safie Burrows, Katherine Jones and Kimberley Hair for assistance in the laboratory and field. We also thank the Director of Fisheries in the Trinidadian Ministry of Agriculture, Land and Marine Resources for permission to collect guppies from the Aripo River for use in our study. Financial support was provided by Concordia University and the Natural Sciences and Engineering Research Council of Canada to G.E. Brown and by Carleton University and NSERC to J.-G.J. Godin. All work reported herein was conducted in accordance the guidelines of the Canadian Council on Animal Care and the laws of Canada, and was approved by the Concordia University Animal Research Ethics Committee (protocol \# AREC-2008BROW).

\section{References}

Amo L, López P, Martín J (2004) Wall lizards combine chemical and visual cues of ambush snake predators to avoid overestimating risk inside refuges. Anim Behav 67: 647-653

Bishop TD, Brown JA (1992) Threat sensitive foraging by larval threespine sticklebacks (Gasterosteus aculeatus). Behav Ecol Sociobiol 31: 133-138

Brown GE (2003) Learning about danger: chemical alarm cues and local risk assessment in prey fishes. Fish Fisheries 4: 227-234

Brown GE, Godin J-GJ (1999) Chemical alarm signals in wild Trinidadian guppies (Poecilia reticulata). Can J Zool 77: 562-570

Brown GE, Adrian JC Jr, Shih ML (2001) Behavioural responses of fathead minnows (Pimephales promelas) to hypoxanthine-3- $N$-oxide at varying concentrations. J Fish Biol 58: 1465-1470

Brown GE, Bongiorno T, DiCapua DM, Ivan LI, Roh E (2006a) Effects of group size on the threat-sensitive response to varying concentrations of chemical alarm cues by juvenile convict cichlids. Can J Zool 84: 1-8

Brown GE, Rive AC, Ferrari MCO, Chivers DP (2006b) The dynamic nature of antipredator behavior: prey fish integrate threat-sensitive antipredator responses with background levels of predation risk. Behav Ecol Sociobiol 61: 9-16 
Chivers DP, Smith RJF (1998) Chemical alarm signaling in aquatic predator-prey systems: a review and prospectus. Écoscience 5: 338-352

Chivers DP, Mirza RS, Bryer PJ, Kiesecker JM (2001) Threat-sensitive predator avoidance by slimy sculpins: understanding the importance of visual versus chemical information. Can J Zool 79: 867-873

Croft DP, Botham MS, Krause J (2004) Is sexual segregation in the guppy, Poecilia reticulata, consistent with the predation risk hypothesis? Environ Biol Fish 71: 127-133

Dupuch A, Magnan P, Dill LM (2004) Sensitivity of northern redbelly dace, Phoxinus eos, to chemical alarm cues. Can J Zool 82: 407-415

Edelaar P, Wright J (2006) Potential prey make excellent ornithologists: adaptive, flexible responses towards avian predation threat by Arabian babblers Turdoides squamiceps living in a migratory hotspot. Ibis 148: 664-671

Endler JA, Houde AE (1995) Geographic variation in female preferences for male traits in Poecilia reticulata. Evolution 49: 456-468

Ferrari MCO, Chivers DP (2006) Learning threat-sensitive predator avoidance: how do fathead minnows incorporate conflicting information? Anim Behav 71: 19-26

Ferrari MCO, Trowell JJ, Brown GE, Chivers DP (2005) The role of learning in the development of threat-sensitive predator avoidance by fathead minnows. Anim Behav 70: 777-784

Ferrari MCO, Rive AC, Macnaughton CJ, Brown GE, Chivers DP (2008) Fixed vs. random temporal predictability of predation risk: an extension of the Risk Allocation Hypothesis. Ethology 114: 238-244

Foam PE, Mirza RS, Chivers DP, \& Brown GE (2005a) Juvenile convict cichlids (Archocentrus nigrofasciatus) allocate foraging and antipredator behaviour in response to temporal variation in predation risk. Behaviour 142: 129-144

Foam PE, Harvey MC, Mirza RS, Brown GE (2005b) Heads up: juvenile convict cichlids switch to threat-sensitive foraging tactics based on chemosensory information. Anim Behav 70: 601-607

Giles N, Huntingford FA (1984) Predation risk and inter-population in anti-predator behaviours in the three-spined stickleback, Gasterosteus aculeatus L. Anim Behav 32: $264-274$

Godin J-GJ, Smith SA (1988) A fitness cost of foraging in the guppy. Nature 333: 323330

Hamilton IM, Heithaus M (2001) The effects of temporal variation in predation risk on anti-predator behaviour: an empirical test using marine snails. Proc R Soc Lond B 268: $2585-2588$

Helfman GS (1989) Threat-sensitive predator avoidance in damselfish-trumpetfish interactions. Behav Ecol Sociobiol 24: 47-58

Helfman GS, Winkleman DL (1997) Threat sensitivity in bicolor damselfish: effects of sociality and body size. Ethology 103: 369-383ß

Hoare DJ, Couzin ID, Godin J-GJ, Krause J (2004) Context-dependant group size choice in fish. Anim Behav 67: 155-164

Kelley JL, Magurran AE (2003a) Learned predator recognition and antipredator responses in fishes. Fish Fish 4: 216-226 
Kelley JL, Magurran AE (2003b) Effects of relaxed predation pressure on visual predator recognition in the guppy. Behav Ecol Sociobiol 54: 225-232

Kelley JL, Magurran AE (2006) Learned defences and counterdefences in predator-prey interactions. In: Brown C, Laland K, Krause J (eds) Fish Cognition and Behaviour. Blackwell, Oxford, pp 28-48

Koivisto E, Pusenius J (2003) Effects of temporal variation in the risk of predation by least weasel (Mustela nivalis) on feeding behavior of field vole (Microtus agrestis). Evol Ecol 17: 477-489

Laurila A, Jujasalo J, Ranta E (1997) Different antipredator behaviour in two anuran tadpoles: effects of predator diet. Behav Ecol Sociobiol 40: 329-336

Lawrence BJ, Smith RJF (1989) Behavioral response of solitary fathead minnows, Pimephales promelas, to alarm substance. J Chem Ecol 15: 209-219

Lima SL, Dill LM (1990) Behavioral decisions made under the risk of predation: a review and prospectus. Can J Zool 68 : 619-640

Lima SL, Bednekoff PA (1999) Temporal variation in danger drives anti-predator behavior: the predator risk allocation hypothesis. Am Nat 153: 649-659

Lima SL, Steury TD (2005) Perception of predation risk: the foundation of nonlethal predator-prey interactions. In: Barbosa P, Castellanos (eds) Ecology of predatorprey interactions. Oxford University Press, Oxford, pp 166-188

Magurran AE (2005) Evolutionary Ecology: the Trinidadian Guppy. Oxford Series in Ecology and Evolution, Oxford University Press, Oxford, pp 52-54

Magurran AE, Seghers BH (1991) Variation in schooling and aggression amongst guppy (Poecila reticulata) populations in Trinidad. Behaviour 118: 214-234

Magurran AE, Seghers BH, Carvalho GR, Shaw PW (1992) Behavioral consequences of an artificial introduction of guppies, Poecilia reticulata, in N. Trinidad: evidence for the evolution of antipredator behaviour in the wild. Proc R Soc Lond B 248: $117-122$

Nordell SE (1998) The response of female guppies, Poecilia reticulata, to chemical stimuli from injured conspecifics. Environ Biol Fish 51: 331-338

O'Steen S, Cullum AJ, Bennett AF (2002) Rapid evolution of escape ability in Trinidadian guppies (Poecilia reticulata). Evolution 56: 776-784

Persons MH, Rypstra AL (2001) Wolf spiders show graded antipredator behavior in the presence of chemical cues from different sized predators. J Chem Ecol 27: 24932504

Quinn GP, Keough MJ (2002) Experimental design and analysis for biologists. Cambridge University Press, Cambridge, UK

Rochette R, Dill LM, Himmelman JH (1997) A field test of threat sensitivity in a marine gastropod. Anim Behav 54: 1053-1062

Sih A, McCarthy TM (2002) Prey responses to pulses of risk and safety: testing the risk allocation hypothesis. Anim Behav 63: 437-443

Sih A, Ziemba R, Harding KC (2000) New insights on how temporal variation in predation risk shapes prey behaviour. Trends Ecol Evol 15: 3-4

Sokal RR, Rohlf FJ (1995) Biometry: The Principles and Practice of Statistics in Biological Research, $3^{\text {rd }}$ edn. Freeman and Company, New York, pp. 446-447

Swaisgood RR, Owings DH, Rowe MP (1999) Conflict and assessment in a predatorprey system: ground squirrels versus rattlesnakes. Anim Behav 57: 1033-1044 
Vainikka A, Jokelainen T, Kortet R, Ylönen H (2005) Predation risk allocation or direct vigilance response in the predator interaction between perch (Perca fluviatilis L.) and pike (Esox lucius L.)? Ecol Freshwat Fish 14: 225-232

Vavrek MA, Brown GE (in press) Threat-sensitive responses to disturbance cues in juvenile convict cichlids and rainbow trout. Ann Zool Fennici

Welton NJ, McNamara JM, Houston AI (2003) Assessing predation risk: optimal behaviour and rules of thumb. Theor Popul Biol 64: 417-430

Wisenden BD, Chivers DP (2006) The role of public chemical information in antipredator behaviour. In: Fish Chemoreception (Ed. by F. Ladich, S.P. Colins, P. Moller \& B.G. Kapoor), pp. 259-278. Enfield, U.S.A.: Science Publisher. 
Table 1: Results of two-way nonparametric ANOVA, testing for the effects of alarm cue concentration, focal population (Upper vs. Lower Aripo guppies) and the two-way interaction for the observed change in area use and shoaling index. $\mathrm{N}=20$ per treatment combination.

\begin{tabular}{lrccc}
\hline & & $\mathrm{H}^{*}$ & $\mathrm{df}$ & $\mathrm{P}$ \\
\hline \multirow{2}{*}{ Area use } & Concentration & 19.85 & 4,190 & $<\mathbf{0 . 0 0 1}$ \\
& Focal population & 0.07 & 1,190 & $=0.79$ \\
& Concentration x Focal population & 2.93 & 4,190 & $=\mathbf{0 . 0 2 2}$ \\
\hline \multirow{2}{*}{ Shoaling index } & Concentration & 10.21 & 4,190 & $<\mathbf{0 . 0 0 1}$ \\
& Focal population & 0.01 & 1,190 & $=0.99$ \\
& Concentration x Focal population & 2.75 & 4,190 & $=\mathbf{0 . 0 2 9}$ \\
\hline
\end{tabular}

* Scheirer-Ray-Hare two-way extension of the Kruskall-Wallis test.

Table 2: Planned contrast values and 95\% confidence intervals for linear and quadratic estimates for Upper Aripo and Lower Aripo guppies exposed to varying concentrations of conspecific alarm cues. $\mathrm{N}=20$ per treatment combination.

\begin{tabular}{rlcccc}
\hline \multicolumn{5}{c}{ Contrast difference } & \multicolumn{2}{c}{$95 \%$ CI } & P \\
\hline \multirow{2}{*}{$\begin{array}{c}\text { Upper Aripo } \\
\text { Area use }\end{array}$} & Linear & 52.50 & Lower & Upper & \\
& Quadratic & 23.33 & 60.69 & 74.32 & $<\mathbf{0 . 0 0 1}$ \\
Shoaling & Linear & -34.11 & -59.02 & -9.20 & $=\mathbf{0 . 0 0 8}$ \\
& Quadratic & -30.92 & -55.83 & -6.00 & $=\mathbf{0 . 0 1 6}$ \\
Lower Aripo & & & & & \\
Area use & Linear & 82.83 & 61.28 & 104.38 & $<\mathbf{0 . 0 0 1}$ \\
& Quadratic & -11.57 & -33.12 & 9.98 & $=0.29$ \\
\multirow{2}{*}{ Shoaling } & Linear & -65.09 & -86.63 & -43.56 & $<\mathbf{0 . 0 0 1}$ \\
& Quadratic & 4.68 & -16.86 & 26.21 & $=0.68$ \\
\hline
\end{tabular}




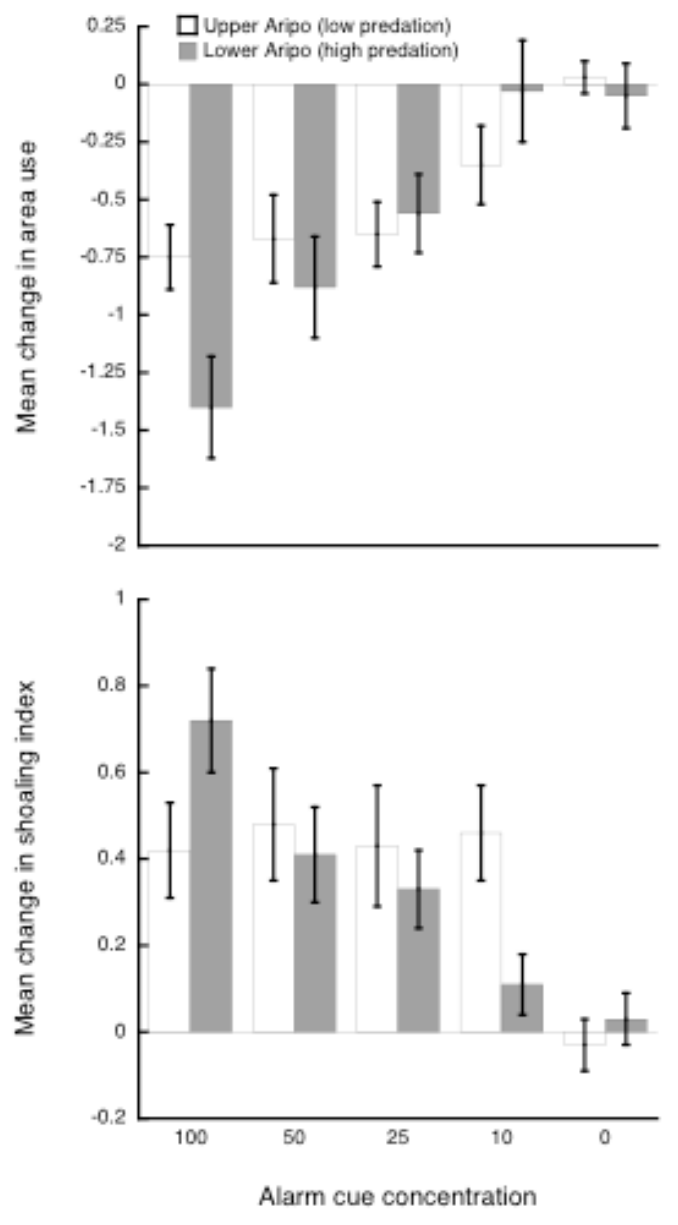

Figure 1: Mean ( \pm SE) change in area use and shoaling index for Upper Aripo (open bars) and Lower Aripo (shaded bars) guppies exposed to conspecific chemical alarm cues at the stock concentration $(100 \%)$, diluted to $50 \%, 25 \%$, or $10 \%$, or a dechlorinated tap water control $(0 \%)$. A reduction in area use and an increase in shoaling index indicate an antipredator response. $\mathrm{N}=20$ per treatment combination. 


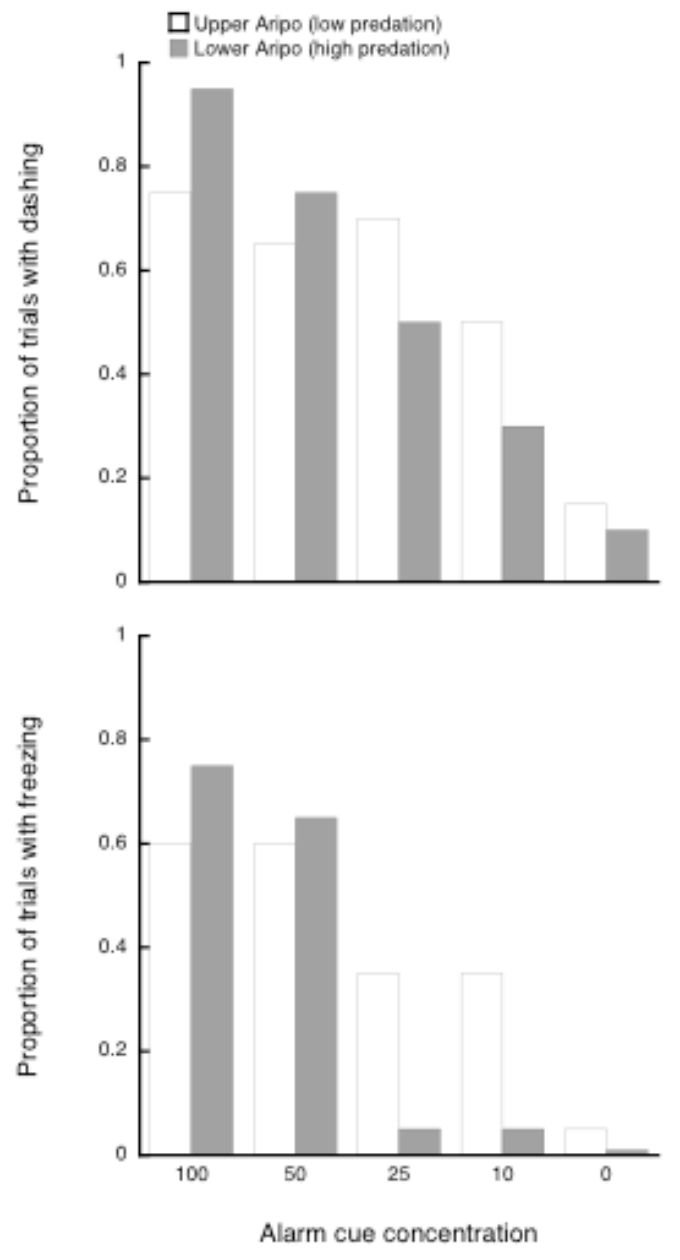

Figure 2: Proportion of trials in which dashing and freezing behaviour were observed for Upper Aripo (open bars) and Lower Aripo (shaded bars) guppies exposed to conspecific chemical alarm cues at the stock concentration (100\%), diluted to $50 \%, 25 \%$, or $10 \%$, or a dechlorinated tap water control $(0 \%) . \mathrm{N}=20$ per treatment combination. 